\title{
NHS referral to a commercial, community-based lifestyle modification programme. Does area of deprivation make a difference?
}

\author{
W.L. Wrieden ${ }^{1}$, H. Williams ${ }^{1}$, J. Thompson ${ }^{2}$, G. Mcfarlane ${ }^{2}$, C. Barnett ${ }^{2}$ and Z. Hellman ${ }^{3}$ \\ ${ }^{1}$ Institute for Health and Welfare Research, Robert Gordon University, Schoolhill, Aberdeen, AB10 1FR, UK, \\ ${ }^{2}$ Directorate of Public Health, NHS Tayside, Kings Cross, Clepington Road, Dundee, DD3 8EA and ${ }^{3}$ Weight Watchers (UK) \\ Ltd, Maidenhead, Berkshire, SL6 2SL, UK
}

Overweight and obesity affects $64.3 \%$ of the adult population in Scotland, with a higher prevalence being observed amongst women in the most deprived communities ${ }^{(1)}$. A community-based lifestyle modification programme delivered by a commercial organisation that follows SIGN $^{(2)}$ and NICE $^{(3)}$ guidance is widely available and has been proven to be a consistently effective intervention for the NHS in England ${ }^{(4)}$, but is not commonly used by NHS Scotland. The aim of this work was to evaluate an NHS referral pilot in Scotland in relation to the Scottish Index of Multiple Deprivation (SIMD).

Health professionals in NHS Tayside offered overweight and obese subjects $(n$ 662) a community-based lifestyle modification programme (Weight Watchers ${ }^{\circledR}$ ), which included; a hypocaloric diet, activity plan, behavioural skill development and support through meetings led by a trained, successful role model. Participants received vouchers to attend 12 weekly meetings, combined with access to online and mobile tools. Data was collected by group leaders and relayed to a central database (weight was measured in meetings on calibrated scales).

Analysis was based on 129 female referrals that commenced the programme between November 2011 and June 2012 and completion was defined as attendance at 9 or more meetings ( $\geq 75 \%$ engagement). Intention-to-Treat analysis, Baseline Observation Carried Forward (ITT BOCF) was carried out where those attending 8 or fewer sessions were assumed to have maintained their baseline weight (weight change $=0$ ). Participants were assigned to one of three groups according to SIMD decile, 1-3 (most deprived), 4-6 and 7-10 (least deprived).

At baseline participants had a median age of 34.2 years with an Inter Quartile Range (IQR) 30.3-43.4. There was a significant difference in the baseline BMI by SIMD with the most deprived group having a median BMI of 36.4 (IQR 32.6 -41.3) versus 33.8 (IQR 31.3-35.9) in the least deprived group $(p=0.018)$. Participants lost a median of $5.90 \mathrm{~kg}$, equating to $5.66 \%$ of their initial body weight (ITT BOCF). Of the 129 women who were referred $85(65.9 \%)$ completed 9 or more sessions. There was no significant difference in attendance, median weight loss, \% body weight loss or BMI change when comparing the most and least deprived groups using the MannWhitney U test.

\begin{tabular}{|c|c|c|c|c|c|c|c|c|}
\hline \multirow[b]{2}{*}{ Age group } & \multirow[b]{2}{*}{$n$} & \multicolumn{2}{|c|}{ Weight $\operatorname{loss}(\mathrm{kg})$} & \multicolumn{2}{|c|}{$\%$ body weight loss } & \multicolumn{2}{|c|}{ BMI change $\left(\mathrm{kg} / \mathrm{m}^{2}\right)$} & \multirow{2}{*}{$\begin{array}{c}\geq 5 \% \text { body weight loss } \\
n(\%)\end{array}$} \\
\hline & & Median & IQR & Median & IQR & Median & IQR & \\
\hline \multicolumn{9}{|l|}{ ITT BOCF } \\
\hline Most deprived & 47 & 5.40 & $0-8.2$ & 5.20 & $0-8.1$ & 2.09 & $0-3.0$ & $24(51.1)$ \\
\hline Least deprived & 46 & 5.90 & $0-7.7$ & 6.35 & $0-9.6$ & 2.19 & $0-3.1$ & $27(58.7)$ \\
\hline \multicolumn{9}{|l|}{ Completers } \\
\hline Most deprived & 33 & 7.30 & $5.0-8.6$ & 7.17 & $4.9-9.3$ & 2.65 & $1.7-3.5$ & $24(72.7)$ \\
\hline Least deprived & 30 & 7.30 & $5.9-11.3$ & 8.33 & $6.5-9.9$ & 2.81 & $2.2-4.0$ & $27(90.0)$ \\
\hline
\end{tabular}

In conclusion, there was no difference in the effectiveness of this community-based lifestyle modification programme by deprivation

Funded by Weight Watchers (UK) Ltd.

1. Bradshaw P, Bromley C, Corbett J et al. (2012) The Scottish Health Survey 2011, vol 1: Adults. Edinburgh:The Scottish Government.

2. Scottish Intercollegiate Guidelines Network (SIGN) (2010) 115: Management of Obesity: A National Clinical Guideline. Edinburgh: SIGN

3. National Institute for Health and Clinical Excellence (NICE) (2006) Obesity: The Prevention, Identification, Assessment and Management of Overweight and Obesity in Adults and Children. London:NICE.

4. Ahern AL, Olson AD, Aston LM et al. (2011) BMC Public Health 11, 434. 